\title{
IMPACT OF RAMAYANA AND MAHABHARATA BROADCASTED DURING LOCKDOWN RESULTING IN SOME COVID-19 SITUATION ACCEPTANCE- CONDUCTED THROUGH ONLINE SURVEY IN INDIA
}

\author{
Patel $\mathrm{K}^{1 *}$ and Binjola $\mathrm{H}^{2}$ \\ ${ }^{I}$ MGCGU, Chitrakoot, Madhya Pradesh India \\ ${ }^{2}$ Graphic Era Hill University Dehradun, Uttarakhand, India
}

\begin{abstract}
The pandemic closure of the COVID-19 state essentially made the human being understand the importance of minimum resources for family, family values and life. Earlier in this short life, we humans surely did not know the importance of gratification and were never contented, and lockdown made us realize that how important these aspects of life were and these aspects should be enjoyed and gratified. The first episode of Ramayana and Mahabharata aired on Doordarshan on $28^{\text {th }}$ March 2020 and the study period of the research has been from $28^{\text {th }}$ March 2020 to $28^{\text {th }}$ April 2020.

During this tenure of lockdown, In Indian channels exasperated connecting families by broadcasting Ramayana and Mahabharata for the audience, engaging their morning and evening prime time slots. These epics are the source of moral comportment, interminable inspiration and constructive ideas for millions of people around the globe. In India along with Puranas and Vedas, the two inordinate epics the Mahabharata and the Ramayana constitute the resilient foundation of glorious Indian culture and civilization.
\end{abstract}

Throughout this research, the researcher wants to test the impact of these epics during the lockdown on the mind of different age groups. The researcher collected the primary data through an online survey and focus group discussions. Therefore, the study should look into the evolving social standards and behaviors of the focus community that has consistently followed the dramatic events.

Keywords: Effect and Impact, Epics, Family Values, Lockdown, Communication, Mindset, Ramayana and Mahabharata

\section{Introduction}

The pandemic of COVID-19 made humans realize the importance of family, friends, home, leisure and need for quality of life. We, humans, had never imagined and thought of a time where we could be locked inside our houses, borders freeze and life came to a halt by being impenetrable in premises. It was for the first time that mother nature also saw animals freely roaming on roads, the environment revitalizing and humans locked inside as if they were locked like animals in zoo. The human race had never imagined that they could ever witness a time like the pandemic of COVID-19. During this lockdown period in India, for amusing and re-installing the roots of Indian culture among humans, retelecast of Ramayana and Mahabharat was done during the period of lockdown. 
Epics have been the strength of Indian culture as they are the prolonged elegiac masterpiece focalized upon a hero who has been archetypal in his attainments. Epics portray the conventional ethnicities which narrate the gallant deeds of heroic figures. Epics have many cultural unfolds and epics tell us about the past of an assemblage, belief or homeland. In Indian scenario when we recall epics there are two very famous epics that come into our mind, the Ramayana and the Mahabharata. Both of these epics were scripted and crafted in Sanskrit language.

If we demeanor at the epic Ramayana so it predominantly has all the values guzzled which are being taught by Indian parents to their children so that their children are raised morally high. These are the quintessential principles that are the pillar of Indian culture. Mahabharata is the longest written epic in Sanskrit language and is divided into eighteen books and is a collection of more than seventy-four thousand verses. Mahabharata is the epic that conveys us that why it is significant and indispensable to accomplish duties that are assigned to us. It throws light on the essential chapters of life that how badly we could affect our life by speaking lie and how we can commit sin. In Mahabharata it is evidently seen that how for individual selfish desires we ruin the entire legacy of the family and how badly each relation with family members gets affected and we deceive our own family in every way and make them stand against each other in the battleground just for personal self-interested and callous motives. These epics have actually taught that how significant it is to be a good human being, prominence of relationships, significance of love, importance of values and ethics and these epics also imbibe the elements of communiqué, patriotism among individuals.

The influence of Ramayana and Mahabharata had been across cultures, countries and centuries. Mahabharata and Ramayana are splendored epic, these epics have illumined the lives of millions divulging lessons in various spheres - societal values, conduct, family and statecraft. These epics have set rubrics for war and peace, for circadian life and during times of crisis propagating the importance of love and sacrifice, virtue, justice and arraigning lust, the evils of covetousness and power, greed. These epics lasted for millennia because their characters stood for dharma and ethics.

These epics also unfolded so many ensigns of women's strength, emotion and their societal stature through characters i.e., Sita, Ahilya, Mandodari, Tara, Draupadi, Kunti, Gandhari and many others. These women characters told us that how women stood strong in their own ways and made society realize their importance and took a stand for their self-respect. These epics taught us all the significant lessons of life and the prominence of principles, scruples, ideologies and moral values.

\section{Ramayana and Mahabharata: A Brief Introduction}

Ramayana and Mahabharata are the greatest epics of India which have influenced the belief system and way of thinking of Hindus. Both the epics are the historical texts of Hindus in Sanskrit. Both the epics have similarities in terms of cultural and historical background. Hinduism firmly believes that it is not a religion but it is a way of living life. In the $5^{\text {th }}$ century, Valmiki wrote Ramayana which comprises of 24,000 verses. Ramayana is the journey of Lord Rama and his triumph over evil. The Ramayana was written by Maharishi Valmiki centuries ago and it narrates the story of Lord Rama who went for exile for 14 years with his wife and brother.

The Mahabharata was written by sage Vyasa and the epic comprises of 200,000 verses and it narrates the triumph of Pandavas over Kauravas. As per Hindus, Hindu gods were present in both the epics 
whether it is Lord Rama, Goddess Sita, Lord Hanuman, Lord Krishna and respectively other gods. As per Hindus both the epics have the same theme of Dharma which means rightful order and morality.

\section{Hypothesis}

Lockdown was the effect of COVID-19 and the broadcast of Ramayana and Mahabharata during lockdown changed and affected the lifestyle of the people.

\section{Objective}

H1. The objective of the study is to understand that the broadcast of Ramayana and Mahabharata during lockdown could bring change in the lifestyle of people.

H2. The objective of the study is also to understand that after the broadcast of epics i.e., Ramayana and Mahabharata, the lifestyle of the people changed or it remained the same as it was before the broadcast of both the epics.

\section{Literature Review}

Dr. Y Ramesh in his paper emphasized on the Influence of Ramayana on the Life, Culture and Literature in India and Abroad Ramayana. He emphasized that how Ramayana and Mahabharat laid the strong foundation of Indian culture and depicted the richness of Indian culture. He mentioned that how these epics influenced the lives of people including the cultural life and behavioral pattern. Ramayana not only made an impact on the minds of Indian people but it also influenced foreign minds as well. Ramayana posh the social and family life.

Ramayana gives us insight into primordial India concerning the political and social state. As it is the primogenital epic so it is an accumulated house of lasting knowledge and a copious source of information. It has made its distinctive abode in the dominion of religious standing and literary development. Epic had its effect on all age groups including the people of old age as well. If we look at the inclusive standing of the epic than it is not only a prevalent epic but it is also a principled cypher of the Hindus. Ramayana can be effortlessly grasped because of its virtuous content. Ramayana imparts that how an ideal son, an ideal king, an ideal father, an ideal mother, an ideal brother, an ideal wife and an ideal husband should conduct and portray their character.

Dr. Y Ramesh in his paper also wrote about the views of the first Prime Minister of Independent India Pt Jawahar Lal Nehru on the two great epics Ramayana and Mahabharat that both the epics dealt with the conquests and civil wars for establishing truth and faith among people and disseminated high ideologies and moralities in the society. Both the epics formed the foundations of various degrees of cultural development.

Dr. Y Ramesh also wrote about the Oxford History of India which mentioned that Ramayana is an epic which is a single narrative poem composed by one author named Valmiki devoted to the great performances of Rama with due regard to the rubrics of poesy. Ramayana is in fact the first example of the Sanskrit Kavya. (Ramesh, 2016). 
U Thein Hen, Chairman of the Burma Historical Commission, mentioned about Ramayana that this epic is not only a literary treasure but the historical epic also speaks loud about relationships of men as husbands and wives, as parents and children, relations and friends, brothers and sisters, rulers and ruled, teachers and the pupil. The way promises are kept by Dashrath in spite of the affection that he had for his son made him stay away from home for 14 years, Rama kept the promise of his father. The sacrifice made by Sumitra, Urmila are incomparable and the sacrifice and sense of devotion displayed by Lakshman is remarkable. If we gawk at Ramayana, we find living examples of the highest moral idealism of life. (Santhanam, 2014)

The entire epic of Ramayana portrayed the spirit of sacrifice, perseverance, devotion, earnestness, trustworthiness, voyage, faithfulness, profound attachment. (Santhanam, 2014). Dr. P.S. Aithal and Dr. K.V.M Varambally in their paper highlighted about the Innovative technological ideas from great epics i.e., Ramayana and Mahabharat and their realization in $21^{\text {st }}$ century. They penned that the war in Mahabharat fought between kauravas and pandavas in Kurukshetra used technologies in the warfare and the techniques then used could be implemented and adopted in $21^{\text {st }}$ century.

The warfare techniques used by Lord Rama could be so valuable for $21^{\text {st }}$ century warfare practices that astounding results could be achieved. Categorizing and accepting such inventive technological concepts which are not patented by anybody. These concepts and designs could be used in civilized society for solving snags of the society (Sreeramana AithalK, 2019). Balakrishnan and AL Munjapan in their paper highlighted the transformational leadership style demonstrated by Sri Rama in Valmiki Ramayana. In their paper, they emphasized that how Lord Rama transformed the lives of millions of Indians, and still in present times oodles are being transformed (Muniapan, 2007) According to Burns, leadership is put forward in two ways i.e., transformational and transactional. (Burns, 1978)

Exchange of value system takes place between the followers and leaders in transactional leadership based on the existing motivations and existing values. The transactional leaders focus on the outcomes, work standards and clarification of tasks. Burn highlighted that how high moral values and higher epitomes of transactional leaders brand the followers to follow them. According to Burn, transactional leaders are the ones that give direction to their followers for achieving high goals and for giving better performance in the traits they excel and encourage towards higher performance. Lord Rama had validated the traits of transactional leadership a thousand years before, way before the model was introduced by Burn and later by Bass and Avolio (1994).

Lord Rama had established 4 dimensions of transactional leadership that consisted of Individualized consideration (IC), Inspirational motivation (IM), Intellectual Simulation (IS) and Idealized Influence (II). Through this paper, the researcher wanted to completely establish the fact that Lord Rama has not only influenced Indian leaders but has been a great example universally and has been a universal icon as well... (Burns, 1978).

Anna Mikhaylovna Subotyalov Mikhail Albertovich Subotyalova in their research paper emphasized about the medical reference pronounced in the ancient Indian epics (Ramayana and Mahabharat).The research paper highlights about the medical and historical phenomenon mentioned in both the ancient Indian epics. (Anna, 2016). 
Medical references were examined through the literary work of both the ancient epics and study of biological and medical heritage was also perceived in the paper. The ancient Indian epics Ramayana and Mahabharat are deliberated and valued as the literary sources for the antiquity of medicine in the post-Vedic period of the medical tradition of Ayurveda. (Sudheendra Honwad, 2017).

The post-Vedic period of Ayurvedic medicine extends between X and VI centuries. Both the epics are the most valued treasure about Indian culture and give evidence about the strong pillars of Indian culture established by these ancient Indian epics. Both the epics have different cultural backgrounds and traditions so they both carry a wide range of information regarding ancient Indian medicine, both epics have diverse natures so both the epics have seen different sets of practices being practiced during their times. In both the epics there have been many medical terms that have been used in Sanskrit and there have been many references to these medical terms ... (Sudheendra Honwad, 2017).

There have been many methods of doctoring discovered in both the epics where testimony has been found of many pathological diseases and methods of treatment and diseases has also been mentioned in both the epics. In these epics, the different sets of Ayurvedic practices have been detailed and described in length. The Ayurvedic practices were based on scientific experiences and observations. Ayurvedic physicians of past generations provided a significant and logical justification of the traditions of their medical system. (Anna, 2016).

According to Titik Sudiatmi, Singgih Subi, Sawitri in their research emphasized on the cultural development, according to them with the development of human mind cultural development takes place and human mind adapts it. For any creation human mind needs imagination and for creation human mind creates the mindset. As far as human work is concerned it could be heirloom material, dance, song, karawitan, jewelries, batik... (Titik, 2018)

Another aspect that they highlighted in their research was the animated movie which could be another way of depicting the themes of Kauravas and Pandawas. People can actually uphold the high principles of Mahabharata through these animated movies and the high moral values could be echoed through these animated movies. These animated versions of Pandawas and Kauravas will eventually lead to the development of culture and it is also clear that culture only develops in the society where its's culture is consumed and they remain rooted to the principles of their culture. These animated movies will utilize human creativity and human imagination... (Titik, 2018).

The philosophy of Pandawas and Kaurawas character give us inspirational role models for the society wherein people could find their inspiration in all the five characters of Pandawas i.e., Yudhishthira, Arjun, Bheem, Nakul and Sehdev. The characters also depict that for the elimination of evil, kindness and truth will always be the winner. In the end truth comes out as the true winner and evil has no place. Here the researchers associated the kindness of Mahabharata with the Javanese philosophy "Wong Salah Bakale Seleh", "wong jujur bakale mujur", "wong goroh bakale sengsara" and through their research gave philosophical perspective also to Javanese people... (Titik, 2018).

This is satisfied with the human mentality dimension that man can never stop and never satisfy his achievement for the continuous growth of his physical and spiritual needs, and continues its efforts towards attaining life 's goals, inner fulfillment and well-being. It depends on the creativity of the artist whether he takes some inspiration from Ramayana and Mahabharat or partial inspiration for the 
creation of the product. Artists have different perspectives of creativity. For the artist the product may include stage layout, place, duration, shape, accompaniment or different ideas for the product.

According to Mayer the product will be accessible for spectator, art devotees, observer and artists. Ramayana and Mahabharata stories could be used as themes for creation of different artistry work and both the epics reflect characters depicting evil and kindness. Both considerations are clearly underlined. Epics will be imitated and followed up on barriers to character education. Saranya and A Balasubramanian in their research paper highlighted the depiction of Hindu mythological characters in cartoons. Animation plays a vital role in grabbing people's attention in spite of gender or age. The pictures and abstract images on the cave walls depict the observations of people of Paleolithic age and hence animation could be traced back (Saranya, 2016).

This research paper highlighted the fact that cartoons have become a major field of research and cartoons are not only a piece of entertainment but they are becoming the major field of exploration and research. Indian mythology is intensely connected with Indian animation. India has a requisite and profligate history and custom of storytelling. Indian kids generally grow up while listening to stories of great kings, gods, and the majority of these stories are from Mahabharata and Ramayana. Moreover, the mythological and historical characters were also the crusaders to the kids in India, as there are imaginations and charm associated with them.

This paved the way to the creation of Indian small screen superheroes such as Chhota Bheem, Krishna, Ganesha, Hanuman, and Luv Kush and so on. Ramayana: The Legend of Prince Rama (1992) is a prominent animation film. A child's mind is critical in grasping and imitating anything they are visible to which is also interesting to them. Therefore, children are found to be following the religious views and practices of the popular Chhota Bheem irrespective of their own religion and practices.

Keshav Patel (2018) in his research paper emphasized on the evolution of communication since ancient times and quotes Narad and Hanuman as examples of great communicators of Indian Hindu mythology and also lays stress that they are the earliest examples of journalism. The researcher through his paper tried connecting the Hindu mythology with the modern media and brings about the valid connection and transformation of media communication for the purpose of social welfare. The author in his research made connections based on descriptions available on characters and identities from Hindu mythology. The researcher emphasized on the social reformation through Indian mythology and modern communication. (Patel, 2018)

\section{Research Gap}

The previous researchers have emphasized on the heroism of both the epics i.e., Ramayana and Mahabharata and also threw light on the moral aspect of both the epics. The previous researchers also focused on the mythological factors of epics, cultural development, traditional values of the epics. The present research paper tries to throw light on the mindset and behavioral pattern of people after watching Ramayana and Mahabharata during the lockdown. This paper tries to understand the impact of both the epics during the lockdown on people of India. 


\section{Materials and Methods: Research Methodology}

The researcher for conducting the research used both qualitative and quantitative methods. In the qualitative method, the researcher conducted focus group discussions, and in the quantitative method researcher conducted survey and collected response from 517 respondents which consisted of 345 males and 172 females. The age group of the respondents was between 20 to 50 years.

The data to test the conceptual model was collected through a field-based survey by administering a structured questionnaire and focus group discussion. The study sample consists of 517 respondents. Out of 517 respondents, 345 are male and 172 are female. The study sample consists of participants up to the age of 20 to 50 years of age.

\section{Results: Data Analysis and Interpretation (data charts are attached in another sheet)}

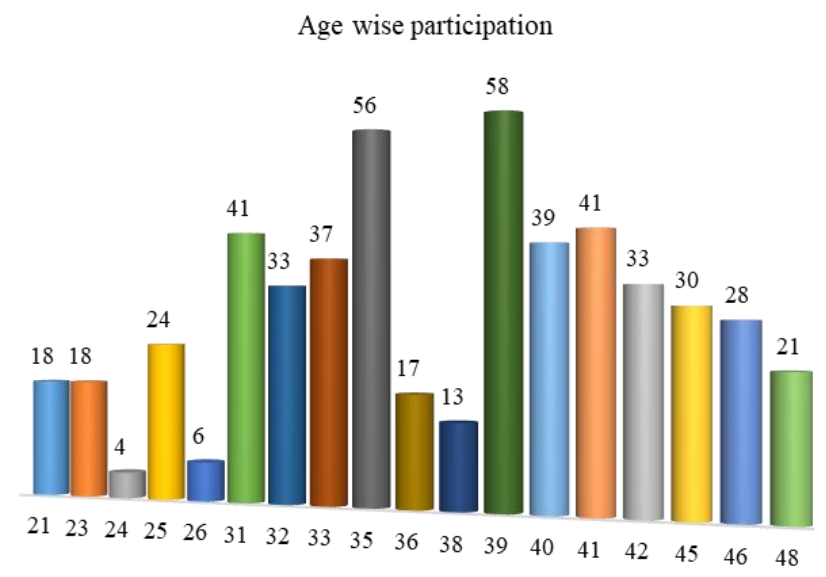

Chart 1: Age Wise Participation of Respondent

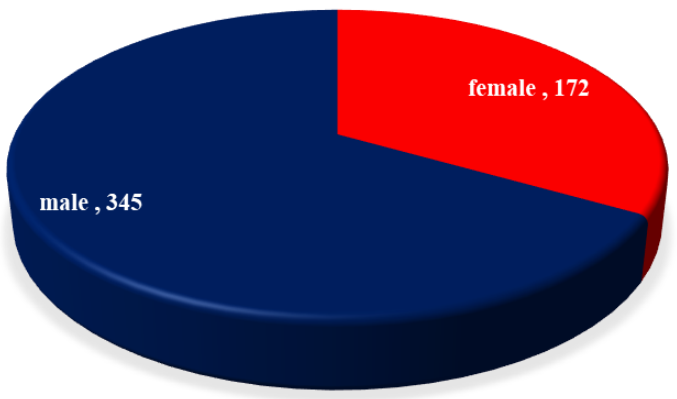

Chart 2: Gender wise participation 


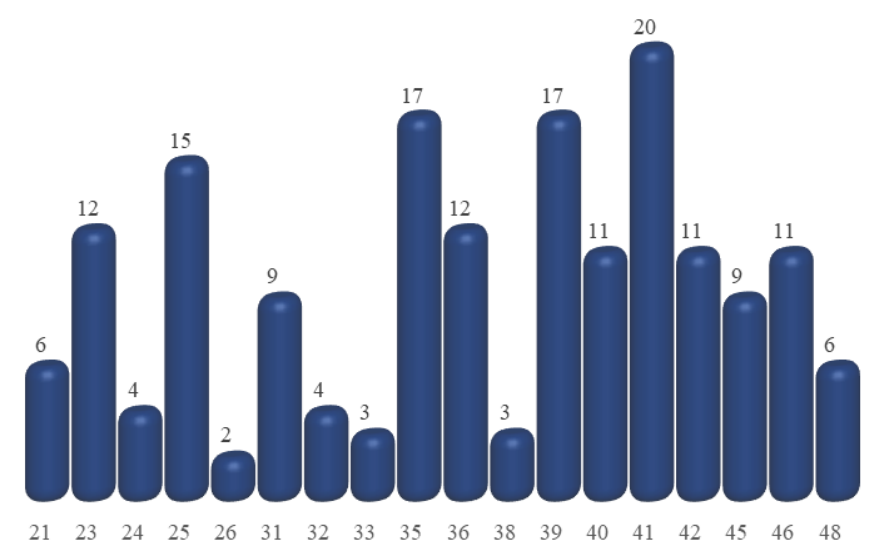

Chart 3: Age wise Female Respondent

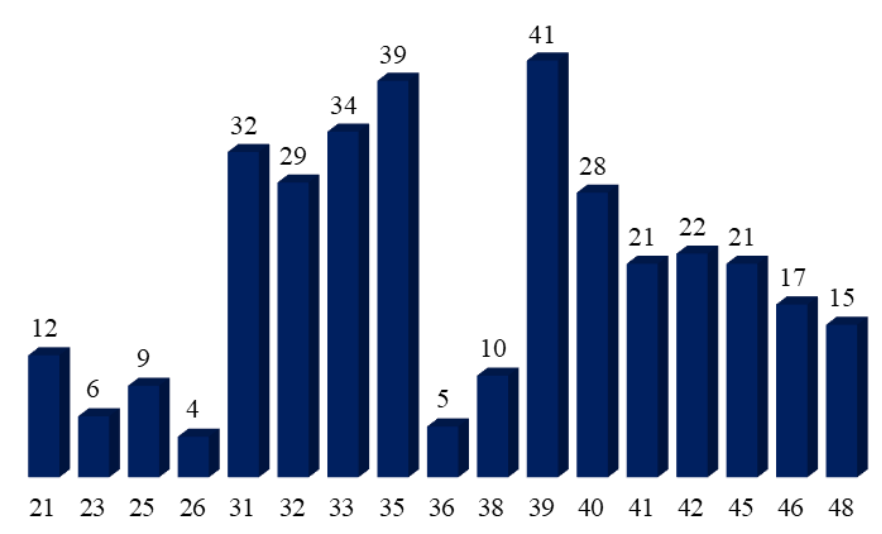

Chart 4: Age Wise Male Respondent

Did you watch television during lock down?

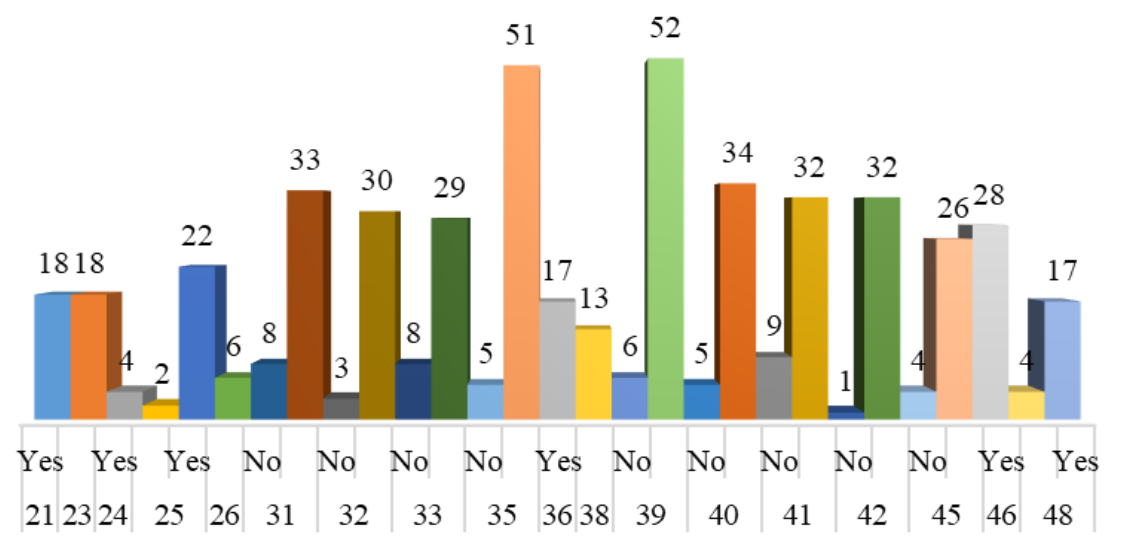

Chart 5: Duration 
Interpretation- In chart 5 respondents responded to the question that did they watch television during a lockdown? Most of the respondents said yes and the majority of the age group is between 33-40 years of age.

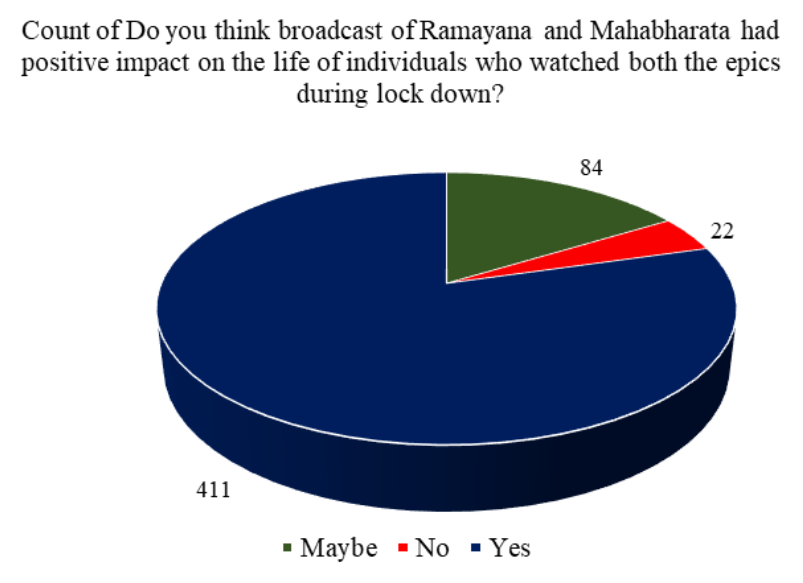

Chart 6: Impact

Interpretation- In chart 517 respondents responded to the question that how Ramayana and Mahabharata had a positive impact on the life of the individuals who had watched both the epics during a lockdown? 411 respondents responded positively that they had a positive impact on their lives after watching both the epics, 84 responded that maybe their life got impacted with both the epics and 22 respondents responded that their lives did not get impacted with the broadcast of both the epics.

\section{Count of Did your eating habits (Non vegetarian to vegetarian) got affected after viewing Ramayana and Mahabharata during lock down?}

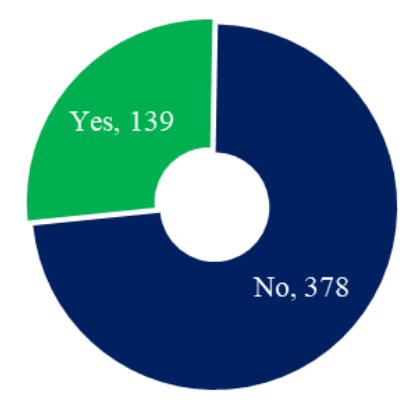

Chart 7: Changing Habits

Interpretation- In chart 517 respondents responded to the question that did their eating habits got affected after watching both the epics during lockdown (from non-vegetarian to vegetarian). 378 
respondents responded to the question that their eating habits did not change from non - vegetarian to vegetarian whereas 139 responded that their eating habits changed from non-vegetarian to vegetarian.

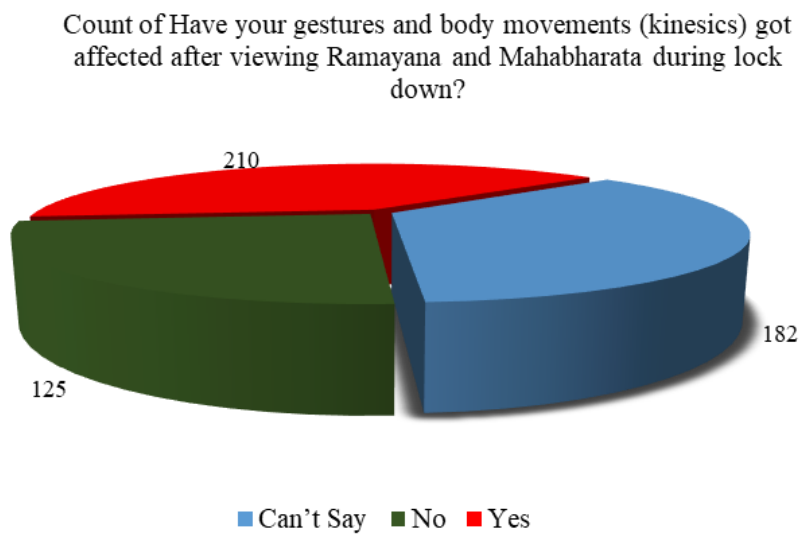

Chart 8: Impact on Gestures and Body Movements

Interpretation- In chart 517 respondents responded to the question that did the respondents find a change in the body language and body movements (kinesics) after watching Ramayana and Mahabharat during the lockdown.210 respondents responded that they find change in their body language and body movements (kinesics) after watching both the epics during the lockdown, 182 responded that might be their body language got impacted after watching both the epics during lockdown, and 125 responded that their body language did not get impacted with both the epics.

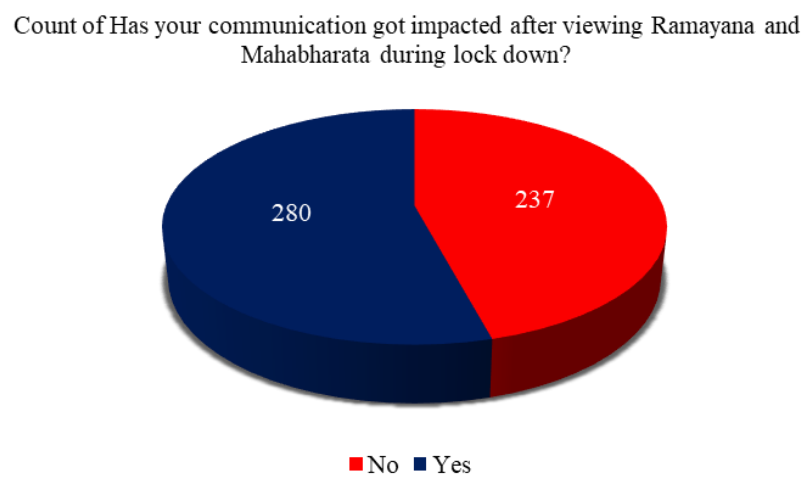

Chart 9: Impact on Communication

Interpretation- In chart 517 respondents responded to the question that did the respondents find a change in their communication after watching both the epics during a lockdown? 280 respondents responded that they find change in their communication whereas 237 respondents responded that they did not find any change in their communication. 
Count of Did you get influenced with the high ideals of Ramayana and Mahabharata after viewing Ramayana and Mahabharata during lock down?

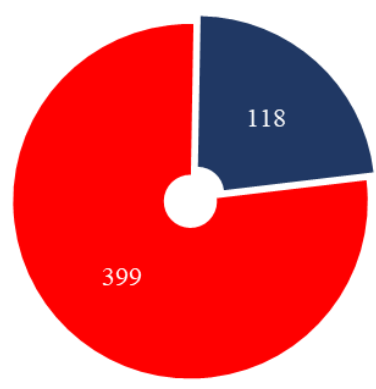

Chart 10: Influence

Interpretation- In chart 517 respondents responded to the question that did the respondents got influenced with the high ideals of Ramayana and Mahabharata after watching both the epics during a lockdown? 399 respondents responded that they got influenced with the high ideals of Ramayana and Mahabharata watched during the lockdown and 118 respondents responded that they did not get influenced with the high ideals of Ramayana and Mahabharat watched during the lockdown.

Count of I pray more often after viewing these TV serials

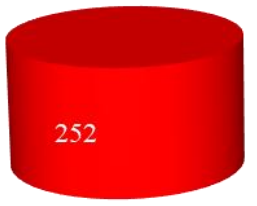

Agree

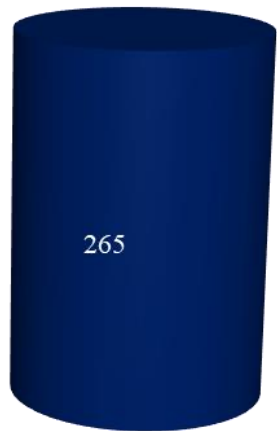

Disagree

Chart 11: Started Praying

Interpretation- In chart 517 respondents responded to the question that after watching both the epics during the lockdown, have they started praying more? 265 respondents responded to the question that they have not started praying after watching both the epics during lockdown whereas 252 responded that they have started praying after watching both the epics during the lockdown. 


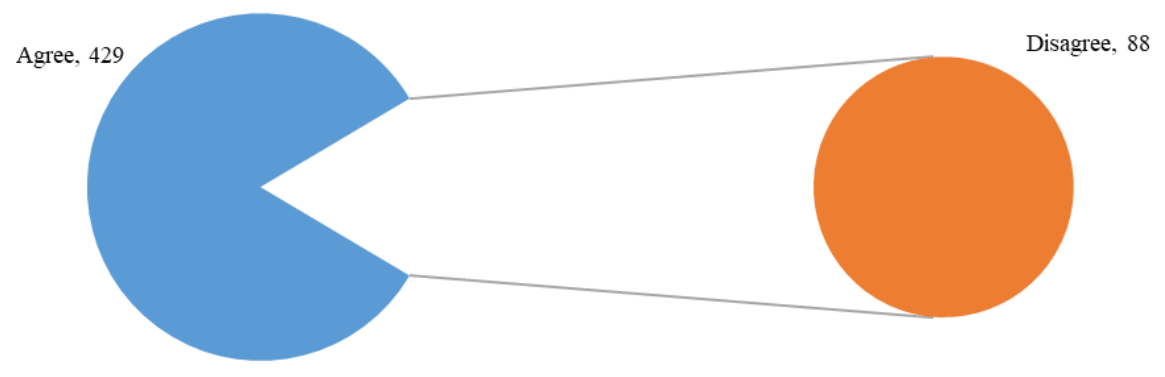

Chart 12: Respect

Interpretation- In chart 517 respondents responded to the question that has the respondents started respecting their elders after watching both the epics during the lockdown.429 respondents responded agreed whereas 88 responded disagreed to the question asked during the research survey.

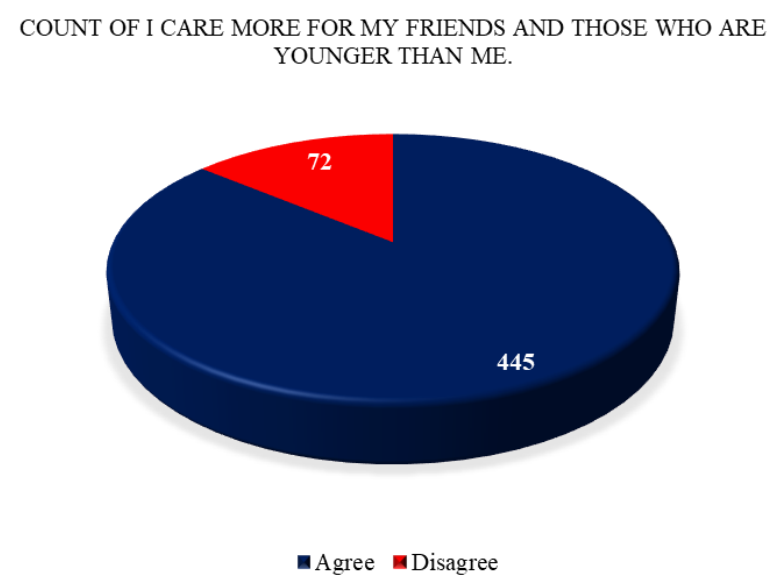

Chart 13: Careing

Interpretation- In chart 517 respondents responded to the question that have they started caring more for their friends and younger ones after watching both the epics during the lockdown. 445 respondents responded agreed that they have started taking more care of their friends and younger ones after watching both the epics during lockdown whereas 72 respondents disagreed to the question and said that they have the same behavior pattern for their younger ones and friends. 


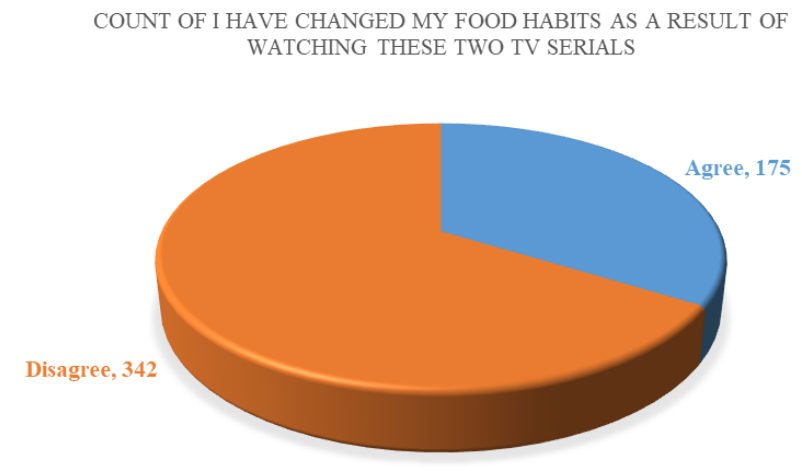

Chart 14: Food Habits

Interpretation- In chart 517 respondents responded to the question that has their eating habits changed after watching Ramayana and Mahabharata during the lockdown.342 respondents disagreed that they have changed their eating habits whereas 175 respondents agreed that they have changed their eating habits after watching both the epics during the lockdown.

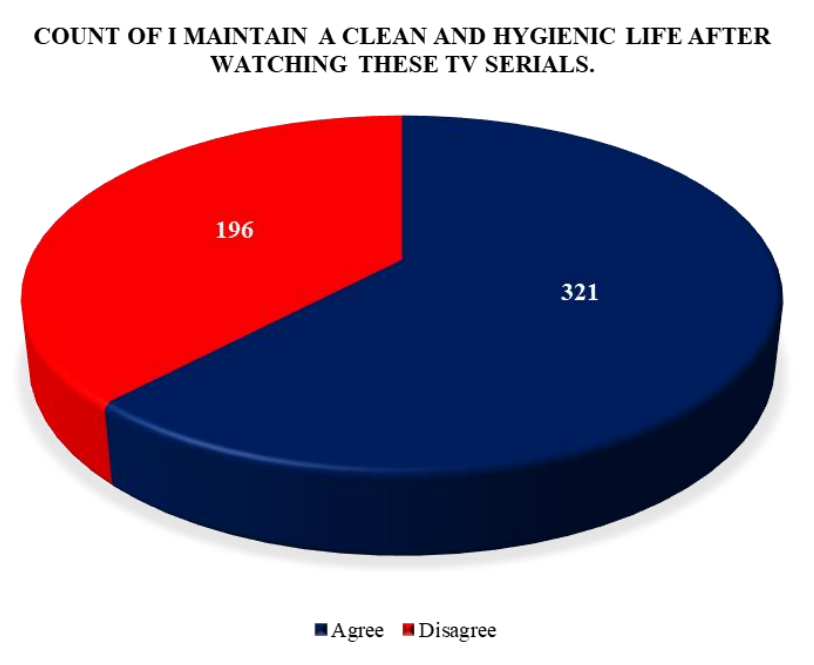

Chart 15: Maintain of Cleaning and Hygienic

Interpretation- In chart 517 respondents responded to the question that whether the respondents have started maintaining a more clean and hygienic life after watching Ramayana and Mahabharat during the lockdown. 321 respondents responded agreed that they have started maintaining a more clean and hygienic life after watching Ramayana and Mahabharat during lockdown whereas 196 respondents responded that their life is similar as it was before and after the lockdown. 


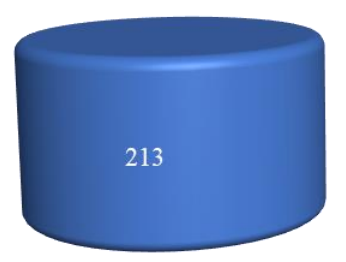

Agree

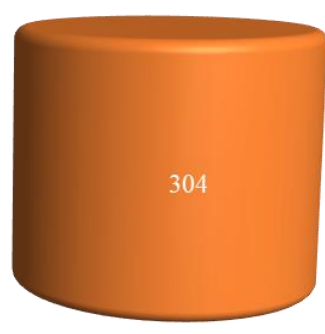

Disagree

Chart 16: Wake Up Timing

Interpretation- In chart 517 respondents responded to the question that they have started waking early after watching Ramayana and Mahabharata during the lockdown.304 respondents disagreed that they have not started waking early after watching both the epics during the lockdown.213 respondents agreed that they have started waking early after watching both the epics during the lockdown.

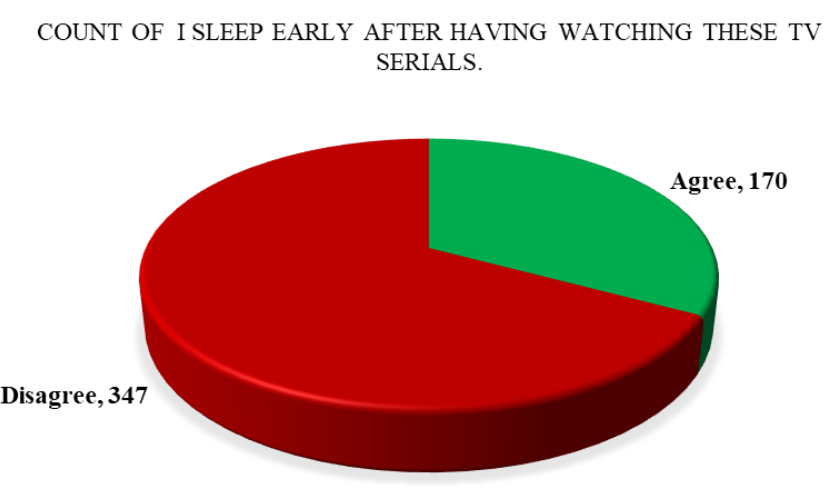

Chart 17 : Sleeping Habit

Interpretation- In chart 517 respondents responded to the question that they have started sleeping early after watching Ramayana and Mahabharata during the lockdown. 347 respondents disagreed that they have not started sleeping early after watching Ramayana and Mahabharata during lockdown whereas 170 respondents agreed that they have started sleeping early after watching Mahabharata and Ramayana during the lockdown. 


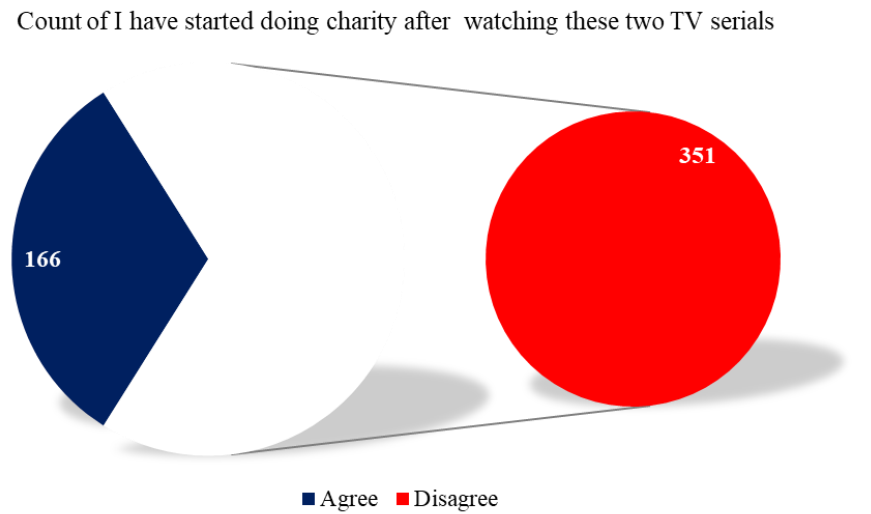

Chart 18: Started Charity

Interpretation- In chart 517 respondents responded to the question that whether respondents have started doing charity after watching both the epics during the lockdown. 351 respondents disagreed that they have not started doing charity after watching both the epics after lockdown whereas 166 respondents agreed that they have started doing charity after watching both the epics during the lockdown.

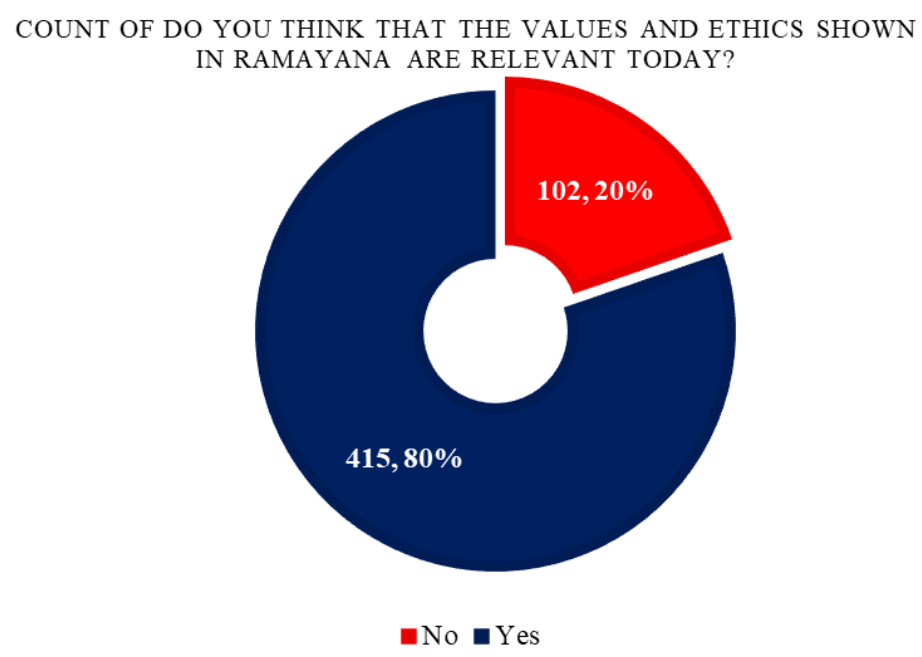

Chart 19: Values and Ethics

Interpretation- In chart 517 respondents responded to the question that whether the values shown in Ramayana are relevant in present times. 415 respondents agreed that the values shown in Ramayana are relevant in present times whereas 102 disagreed that the values shown in Ramayana are not relevant in present times. 


\section{Count of Do you think the ethics and values shown in Mahabharata are} relevant today?

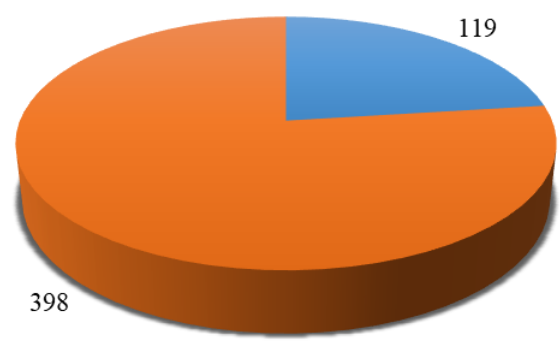

No $\square$ Yes

\section{Chart 20: Ethics and Values}

Interpretation- In chart 517 respondents responded to the question that whether the values shown in Mahabharata are relevant in present times. 398 respondents agreed that the values shown in Mahabharata are relevant in present times whereas 119 disagreed that the values shown in Mahabharata are not relevant in present times.

Count of To what extent has the Ramayana and Mahabharata broadcast affected your lifestyle?

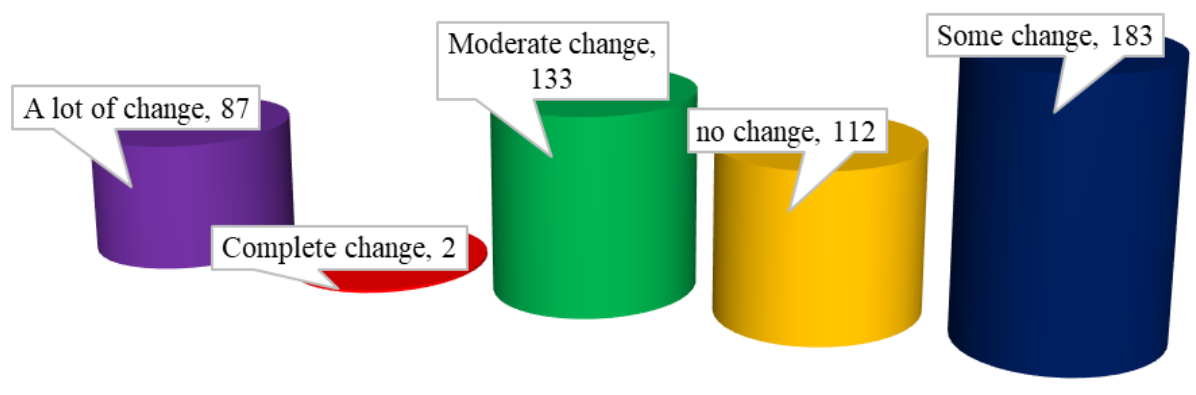

Sum of age by To what extent has the Ramayana and Mahabharata

broadcast affected your lifestyle?

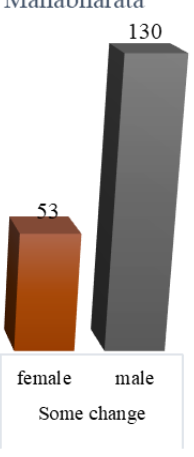

Chart 21: Affect on Lifestyle 
Interpretation- In chart 517 respondents responded to the question that whether the broadcast of both the epics had changed the lifestyle of the respondents during the lockdown.183 respondents responded that they experienced a change in their lifestyle whereas 133 had moderate changes, 112 find no change in their lifestyle, 87 respondents found a lot of changes and 2 felt a complete change.

Count of Do you think broadcast of Ramayana and Mahabharata had positive impact on the life of individuals who watched both the epics during lock down?

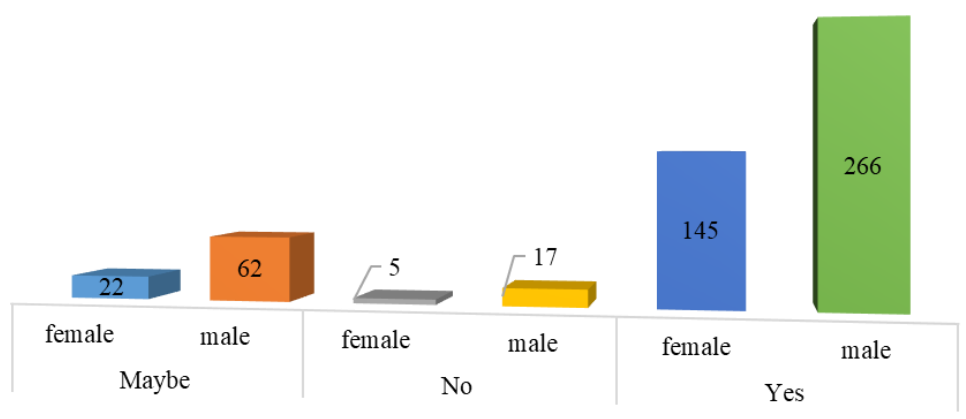

Chart 22: Positive Impact on the Life

Interpretation- In chart 517 respondents responded to the question that whether the broadcast of Ramayana and Mahabharata had a positive impact on the life of individuals who watched both the epics during a lockdown? 266 males and 145 females experienced the positive changes whereas 62 males and 22 females responded that they might have experienced changes and 17 males and 5 females experienced no changes.

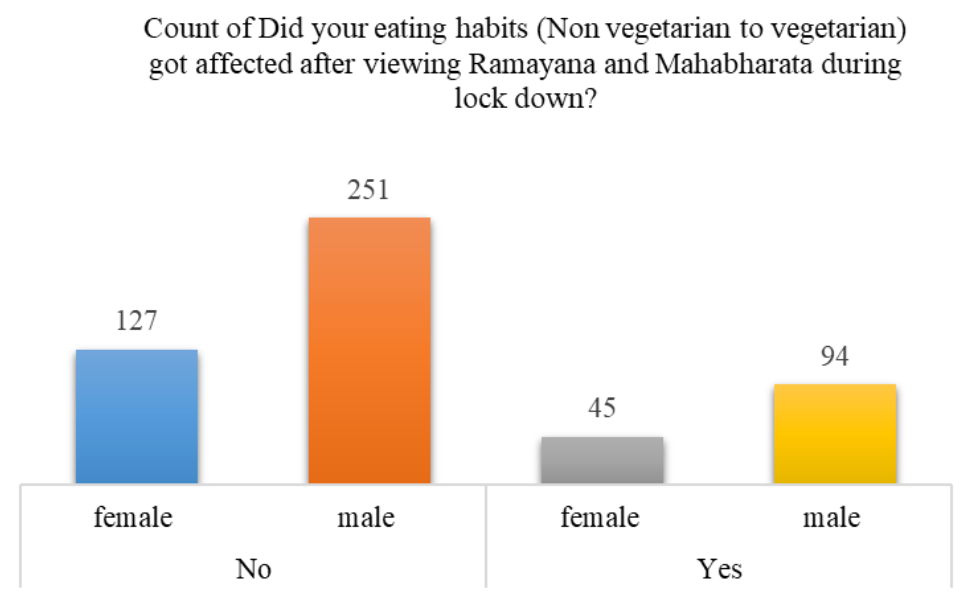

Chart 23: Affect on Eating Habit

Interpretation- In chart 517 respondents responded to the question that whether their eating habits changed during lockdown after watching both the epics.251 male and 127 females experienced no changes in their eating habits whereas 94 male and 45 females experienced changes in their eating habits. 


\section{Focus Group}

In this research for observing the attitude of the people and for understanding the sentiments of the people, we did a focus group study wherein we had people from Madhya Pradesh and Dehradun among the age group of 20-30, 30-40 and 40-50. We asked five questions from each participant in each focus group and tried understanding the effect of Ramayana and Mahabharata broadcast during the lockdown on the individuals.

\section{0-30 Group- Participants (Ruchi Patel-25, MP, Nitin Anand-21, Dehradun)}

\section{Nitin Anand-20, Dehradun}

1. Question-Did you watch the broadcast of Ramayana and Mahabharata during a lockdown?

Answer-Yes, I did and really felt nice after watching the epics.

2. Question- Did the high ideals of Ramayana and Mahabharata impact your life?

Answer- Yes, I really applauded and appreciated the high ideals of Ramayana and Mahabharata. I am trying to incorporate the ideals in my life.

3. Question-Did your eating habits change after watching Ramayana and Mahabharata during lockdown?

Answer- Yes, surely after watching the epics I have turned myself into a vegan and love being a vegetarian.

4. Question-Did your lifestyle change after watching Ramayana and Mahabharata during lockdown?

Answer- No, not really as my lifestyle is all same. It has not changed.

5. Question- Do you think that the broadcast of epics should be regular for the audience.

Answer- I completely agree that the broadcast of epics should be regular for the audience.

\section{Ruchi patel-25, MP}

1. Question-Did you watch the broadcast of Ramayana and Mahabharata during lockdown?

Answer-Yes, I did

2. Question- Did the high ideals of Ramayana and Mahabharata impact your life?

Answer- Maybe, means I am not sure whether the high ideals of Ramayana and Mahabharat impacted me or not.

3. Question-Did your eating habits change after watching Ramayana and Mahabharata during a lockdown? 
Answer-No, not at all my eating habits are all same as they were before lockdown. I completely relish non-vegetarian meals and I firmly believe that the broadcast of both the epics had nothing to do with my eating habits.

4. Question-Did your lifestyle change after watching Ramayana and Mahabharata during a lockdown?

Answer- No, not specifically as my lifestyle is all same before and after lockdown.

5. Question- Do you think that the broadcast of epics should be regular for the audience.

Answer- Maybe, it depends on the acceptance of the audience and if it is appreciated among people than it must be broadcast regularly.

30-40 Group- Participants (Shivani Arora-32, MP, Sandeep Tiwar-35, Dehradun)

\section{Shivani Arora -32, MP}

1. Question-Did you watch the broadcast of Ramayana and Mahabharata during lockdown?

Answer-Partially, like when I get time from my routine chores.

2. Question- Did the high ideals of Ramayana and Mahabharata impact your life?

Answer- Maybe, I am not sure of the impact of Ramayana and Mahabharata on my life.

3. Question-Did your eating habits change after watching Ramayana and Mahabharata during lockdown?

Answer-No, my eating habits are all same before and after lockdown. Nothing changed in my eating habits.

4. Question-Did your lifestyle change after watching Ramayana and Mahabharata during lockdown?

Answer-No, my lifestyle is all same before and after lockdown

5. Question- Do you think that the broadcast of epics should be regular for the audience.

Answer- Yes, the broadcast of epics is really good for the moral upliftment of the society and the broadcast of epics should be regular for the audience.

\section{Sandeep Tiwari-35, Dehradun}

1. Question-Did you watch the broadcast of Ramayana and Mahabharata during lockdown?

Answer-Yes, I have been regularly following both the epics on Doordarshan and DD-Bharati.

2. Question- Did the high ideals of Ramayana and Mahabharata impact your life? 
Answer- Yes, I completely agree that high ideals of Ramayana and Mahabharata have impacted my life. Both epics have been truly inspiring.

3. Question-Did your eating habits change after watching Ramayana and Mahabharata during lockdown?

Answer-Yes, my eating habits have changed from non-vegetarian to vegetarian. I must tell you that I am really enjoying this change.

4. Question-Did your lifestyle change after watching Ramayana and Mahabharata during lockdown?

Answer-Yes, I am finding change in my lifestyle after watching these epics regularly.

5. Question- Do you think that the broadcast of epics should be regular for the audience.

Answer- Yes, I firmly believe that if we really want society to hold traditional and cultural values then it becomes really important that we broadcast epics regularly.

40-50 Group- Participants (Amit Sharma-42, MP, Jasleen Gandhi-47, Dehradun)

\section{Amit Sharma-42, MP}

1. Question-Did you watch the broadcast of Ramayana and Mahabharata during lockdown?

Answer-No, I have not been following both the epics during lockdown.

2. Question- Did the high ideals of Ramayana and Mahabharata impact your life?

Answer-No, as I have not watched the epics so can't comment on the said statement.

3. Question-Did your eating habits change after watching Ramayana and Mahabharata during lockdown?

Answer-No, there have been no changes in my eating habits.

4. Question-Did your lifestyle change after watching Ramayana and Mahabharata during lockdown?

Answer-No, there have been no changes.

5. Question- Do you think that the broadcast of epics should be regular for the audience.

Answer- Yes, I believe that whether I have not followed both the epics during lockdown but in my perspective, epics should be broadcasted regularly for the audience.

\section{Jasleen Gandhi-47, MP}

1. Question-Did you watch the broadcast of Ramayana and Mahabharata during lockdown?

Answer-Yes, I have been following both the epics regularly during lockdown. 
2. Question- Did the high ideals of Ramayana and Mahabharata impact your life?

Answer-Yes, I completely believe that both the epics have impacted my life in a beautiful way.

3. Question-Did your eating habits change after watching Ramayana and Mahabharata during lockdown?

Answer-Yes, there have been changes in my eating habits have adopted vegetarian eating habits.

4. Question-Did your lifestyle change after watching Ramayana and Mahabharata during lockdown?

Answer-Yes, my lifestyle has changed after watching both the epics during lockdown.

5. Question- Do you think that the broadcast of epics should be regular for the audience.

Answer- Yes, these epics will help in holding our roots strong so they should be regularly broadcast for the audience.

\section{Discussion}

The researcher through his research was able to comprehend the research problem by surveying 517 people. Through the research, it could be visibly seen that the broadcast of Ramayana and Mahabharata had a positive impact on people's lifestyle, communication, body language, moral values and on important aspects of individuals. It could be seen that the broadcast of epics made people come back to their cultural roots. The broadcast of epics made people apprehend that how our motherland had been culturally and morally rich. The high ideals of Ramayana and Mahabharata made an optimistic impact on people's life and the research also made it obvious that from time to time such epics should be broadcasted for social upliftment and for social improvement and mobility.

\section{Scope For Further Research}

The researcher in this research studied the impact of Ramayana and Mahabharat broadcasted during the lockdown and the results were very interesting. In the same manner, other researchers could conduct the study based on their regions and the programs broadcasted during lockdown. This study could be conducted nation-wise, region-wise, Programme wise, and as per the interest of the people. The results attained could be very interesting and a new research study could take place if we further broaden the horizon of the research.

\section{Acknowledgments}

The researcher acknowledges the platform given by TIIKM in the pandemic times. The stage given by TIIKM has been remarkable as they have given notable platforms to researchers in the tough times of COVID crisis. 


\section{Declaration Of Interest Statement}

There is no conflict of interest in this research. There is no funding involved in this research. The research has been purely conducted by the researcher for TIIKM and the data is absolutely original and has not been copied from anywhere.

\section{Limitation}

The research presents the conceptual analysis of the theoretical data and the data collected through a survey and focus group discussions. During the research due to the pandemic of COVID-19, the researcher was not able to collect data physically. Data was collected through an online survey and telephonic interaction with the focus group. As Ramayana and Mahabharata are firmly associated with the religious sentiments of the people so, during the research, the researcher has not hurt the religious sentiments of the people by touching the religious aspects and has not introspected the religious sentiments. The sentiments of the larger population have been understood by researching 517 people and due to COVID-19 the research was not extended to different parts of the country and had geographical constraints.

\section{Recommendations}

This study is beneficial in understanding the mindset of the people and their acceptance of epics. This study gives the inside that howsoever we modernize ourselves but we are still deeply rooted to our culture and tradition. This study gives a new perspective for cultural and traditional studies. This study was only conducted in India on 517 people, so the researcher recommends that this study could be conducted on a larger population, and the area of the study could be broadened. This study could also be implemented on other nations as well.

\section{References}

Anna Mikhaylovna Subotyalov, M. A. (2016). Medical reference in the epics of ancient India (Ramayana \& Mahabharata). Novosibirsk State Pedagogical University Bulletin, 6(3), 96-103. doi:http://dx.doi.org/10.15293/2226-3365.1603.09

Burns, J. M. (1978). Transformational leadership. Retrieved 08 15, 2020, from langston.edu.

Dr.Y.RAMESH. (2016, 08). Influence of Ramayana on the Life, Culture and Literature in India and Abroad Ramayana. International Journal of Engineering Science and Computing, 2453-2459.

Muniapan, B. A. (2007). Transformational leadership style demonstrated by Sri Rama in Valmiki Ramayana. Int. J. Indian Culture and Business Management, 1(2), 104-115. Retrieved 08 11, 2020

Patel, K. (2018). Impact of Advancements in Technological Aids in Communication Media in Bringing About Social Reformation. The Global Conference on Journalism and Mass Communication, Communication,, 1, p. 105. Colombo. doi:10.17501/globalmedia.2018.1101

Santhanam, K. (2014, 02 14). Effects of the epic. Retrieved 08 21, 2020, from thehindu.

Saranya, A. B. (2016). Depiction of Hindu mythological characters in cartoons: A case study of Chhota Bheem. I J A B E R,, 14(12), 8511-8518. Retrieved 07 25, 2020 
Sreeramana AithalK, V. M. (2019). innovative technological ideas from great indian epics and their realization in $21^{\text {st }}$ century . Inventions in ICT \& its Impact on Management Social Sciences and Education, 19.

Sudheendra Honwad, R. (2017, 07). ORIGIN \& DEVELOPMENT OF AYURVEDA. International Ayurvedic Medical Journal, 5(6), 2620-2627. Retrieved 07 05, 2020

Titik Sudiatmi, S. S. (2018). MOVIE ANIMATION OF PANDAWA AND KURAWA CHARACTERS MANIFESTING THE JAVANESE LIFE PHILOSOPHY. International Journal of Social Sciences, Humanities and Education, 2(2), 1-7. Retrieved 07 25, 2020 